\title{
Urban informatics, governmentality and the logics of urban control
}

\author{
Kitchin, R. ${ }^{1}$, Claudio Coletta ${ }^{1}$, and Gavin $\mathrm{McArdle}^{2}$
}

1. National Institute for Regional and Spatial Analysis, National University of Ireland Maynooth, Ireland

2. School of Computer Science, University College Dublin, Ireland

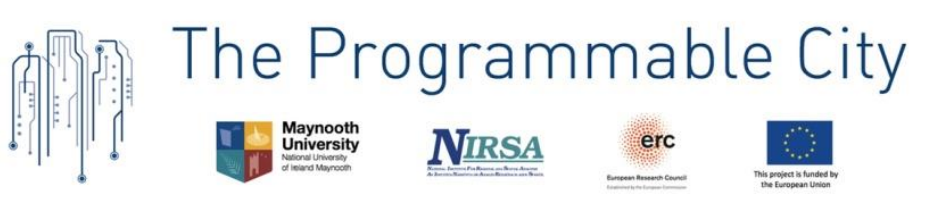

The Programmable City Working Paper 25

http://progcity.maynoothuniversity.ie/

7 February 2017

For Luque-Ayala, A. and Marvin, S. (eds) Control Room: Nodes in the Networked City. Routledge, London.

Published as an open access pre-print on SocArXiv: https://osf.io/preprints/socarxiv/27hz8/

\begin{abstract}
In this paper, we examine the governmentality and the logics of urban control enacted through smart city technologies. Several commentators have noted that the implementation of algorithmic forms of urban governance that utilize big data greatly intensifies the extent and frequency of monitoring populations and systems and shifts the governmental logic from surveillance and discipline to capture and control. In other words, urban governmentality is shifting from subjectification - molding subjects and restricting action - to modulating affects, desires and opinions, and inducing action within prescribed comportments. We examine this contention through an examination of two forms of urban informatics: city dashboards and urban control rooms and their use in urban governance. In particular, we draw on empirical analysis of the governmental logics of the Dublin Dashboard, a public, analytical dashboard that displays a wide variety of urban data, and the Dublin Traffic Management and Incident Centre (TMIC) and its use of SCATS (Sydney Coordinated Adaptive Traffic System) to control the flow of traffic in the city. We argue that there is no one governmentality being enacted by smart city technologies, rather they have mutable logics which are abstract, mobile, dynamic, entangled and contingent, being translated and operationalized in diverse, context-dependent ways. As such, just as disciplinary power never fully supplanted sovereign power, control supplements rather than replaces discipline.
\end{abstract}

Key words: smart cities, governmentality, logics, urban informatics, city dashboards, traffic control 


\section{Introduction}

City administrations have long generated data about people and places and used them to manage and control urban populations, steer operations and services, and guide and evaluate public policy. In recent years, there has been a step change in the production of urban data through the development of urban informatics and smart city technologies. Batty (2013: 3) describes urban informatics as the 'application of computers to the functioning of cities' and 'the ways in which computers are being embedded into cities'. This includes the use of various information systems and control rooms, the networking and digital enhancing of traditional infrastructure, the deployment of the internet of things wherein a variety of networked devices, sensors, cameras, transponders, and actuators are woven into the urban fabric, and wide-scale adoption of mobile/locative media. Collectively, these technologies produce and manage streams of big data that are augmenting and mediating the operation and governance of urban systems. In this chapter, we are interested in two forms of urban informatics: city dashboards and urban control rooms, both of which make extensive use of visual analytics and dashboard interfaces. In particular, we are concerned with how they are producing new forms of urban governance and reshaping contemporary governmentality.

A number of scholars have argued that a key transformative effect in the adoption of urban informatics and the production of smart cities is the reconfiguring of urban governmentality (Kitchin and Dodge 2011; Braun 2014; Gabrys 2014; Klauser et al. 2014; Vanolo 2014; Davies 2015; Sadowski and Pasquale 2015; Luque-Ayala and Marvin 2016; Krivy 2016). The general conclusion is that algorithmic forms of governance are producing a shift from disciplinary forms of governmentality towards social control. For Foucault (1991), governmentality is the logics, rationalities and techniques that render societies governable and enable government and other agencies to enact governance. Every society is thus organised and managed through a system of government and governance underpinned by a mode of governmentality. The nature of governmentality mutates over time and periodically its form can shift fundamentally in character. For example, in the shift from a feudal society to modern society, wherein more systematised means for managing and regulating individuals through centralised and institutionalised control were introduced.

Through a series of essays, Foucault $(1977,1978,1991)$ argued that modern governmentality - through its interlocking apparatus of institutions, administration, law, technologies, social norms and spatial logics - exercises a form of disciplinary power designed to corral and punish transgressors and instil particular habits, dispositions, expectations and self-disciplining. A key aspect of disciplinary governmentality is that people 
know that they are subject to monitoring and enrolment in calculative regimes. This has entailed the rollout of procedures and technologies for the systematic, wide-scale generation and assessment of data about them and their actions. In general, monitoring has been periodic, somewhat haphazard, and enacted by people working for institutions.

The implementation of algorithmic forms of governance that utilize big data greatly intensifies the extent and frequency of monitoring and shifts the governmental logic from surveillance and discipline to capture and control (Deleuze 1992; Agre 1994) through the use of systems that are distributed, ubiquitous and increasingly automated, automatic and autonomous in nature (Dodge and Kitchin 2007). Here, people become subject to constant modulation through software-mediated systems, such as a transport network controlled by an intelligent transport system or a fuel consumption gauge in a car that continually displays miles per litre, in which their behaviour is directed explicitly or implicitly nudged, rather than being (self)disciplined. In these examples, driving is modulated by the traffic light sequencing and the act of driving itself becomes a site of administration (Dodge and Kitchin 2007; Braun 2014). In other words, governmentality is no longer solely about subjectification (molding subjects and restricting action) but about control (modulating affects, desires and opinions, and inducing action within prescribed comportments) (Braun 2014; Krivy 2016). Rather than power being spatially confined and periodic, 'exercised across a network of heterogeneous institutional enclosures - each one possessing its own self-enclosed monitoring system that envelops the targeted population in a homogeneous disciplinary effect', systems of control are distributed, interlinked, overlapping and continuous, enabling institutional power to creep across technologies and pervade the social landscape (Martinez 2011: 205). For example, as Davies (2015) notes with respect to Hudson Yards, a smart city development in New York that is being saturated with sensors and embedded computation, residents and workers will be continually monitored and modulated across the entire complex by an amalgam of interlinked systems. The result will be a quantified community with numerous overlapping calculative regimes designed to produce a certain type of social and moral arrangement, rather than people being regulated into conformity within certain institutional enclosures (such as schools and work places) (Martinez 2011; Davies 2015).

Many smart city technologies enact social control because they are cybernetic systems that function through dense and simultaneous feedback that modulates the performance of an infrastructure and those captured within it (Braun 2014; Davies 2015; Krivy 2016). From this perspective, the city becomes a system of systems, as initially argued by cybernetians fifty years ago (Forrester 1969) and reanimated more recently in smart city discourses (Townsend 
2014). Krivy (2016) contends that contemporary smart city systems are forms of secondorder cybernetics that utilise positive feedback in a continuous process of self-organization. That is, they recognize: the open, non-linear, emergent and complex properties of cities and expect unintended consequences and side-effects; and that people act as 'sensors' that feedback and shape the unfolding management rather than simply being acted upon. Within these systems ' $[\mathrm{t}]$ he cumulative character of data streaming effectuates positive feedback loops whereby certain behaviours are amplified while others are hindered', and social change occurs through the 'accumulation of multifarious but infinitesimal behavioural adjustments' (Krivy 2016: 15). As noted by Sadowski and Pasquale (2015), this shift to control has also been accompanied by a shift from a social contract between the state and citizens, to corporate contract wherein city services are delivered through public-private partnerships or private entities only.

The tactics and techniques of governmentality are highly varied, for example, utilising a range of technologies, each of which can be configured and deployed in different ways. More fundamentally, it is argued that the nature of governmentality can be diverse, with several related and overlapping forms of governmentality enacted and promoted by different entities at work at the same time. For example, just as disciplinary power never fully replaced sovereign power, control might supplement rather than becoming dominant to discipline (Davies 2015; Sadowski and Pasquale 2015). In other words, just as there are varieties of capitalism (Peck and Theodore 2007) and varieties of neoliberalism (Larner 2003; Brenner et al., 2010) - shaped by national and local political economies, political ideology, state policies, institutional cultures, market practices, legal frameworks, public sentiment, etc. there are varieties of governmentalities (Ong 2006). Indeed, Ong (2006) argues that contemporary governmentalities associated with neoliberalism are not uniform and universal global logics. Rather they have mutable logics which are abstract, mobile, dynamic, entangled and contingent, being translated and operationalized in diverse, context-dependent ways. From this perspective, forms of power and control invested in and enacted by smart city technologies are mutable, even within classes of technologies, driven by differing value systems and dependent on local and national institutional politics and policies and practices of deployment. That said, they are nonetheless framed within the wider political, social, economic and legal landscape. In other words, while civic hacking and urban operating systems might fundamentally differ with respect to the work that they perform, both are situated within and reproduce neoliberal forms of governance and governmentality. 
The challenge then is to map the forms and practices of governmentality with respect to the smart city - what Vanolo (2014) terms 'smartmentality' - detailing the mutable ways in which the logics of power and control are formulated and enacted. We provide an initial exploration of such a position through an examination of two forms of urban informatics. In the first section, we document in general terms city dashboards and urban control rooms and their use in urban governance. We then extend this analysis and critique by considering the logics of power and control embedded within and exerted by each and their (re)production of certain modes of governmentality. We do this through an examination of the Dublin Dashboard, a public, analytical dashboard that displays a wide variety of urban data and the Dublin Traffic Management and Incident Centre (TMIC) and its use of SCATS (Sydney Coordinated Adaptive Traffic System) to control the flow of traffic in the city.

\section{Urban informatics}

\section{City dashboards}

City dashboards use visual analytics - dynamic and/or interactive graphics (e.g., gauges, traffic lights, meters, arrows, bar charts, graphs), maps, 3D models and augmented landscapes - to display information about the trends, performance, structure, and patterns of cities. In effect, selected data about cities are displayed on a screen using data visualisations, which in many cases are interactive (e.g., selecting, filtering, and querying data; zooming in/out, panning and overlaying; changing type of visualisation or simultaneously visualising data in a number of ways). In some cases, selected data are 'consolidated and arranged on a single screen so the information can be monitored at a glance' (Few 2006: 34). Here, a city dashboard operates like a car dashboard or plane cockpit display providing critical information in a single view (Gray et al. 2014). Analytical dashboards are more extensive in scope and are hierarchically organised to enable a plethora of interrelated dashboards to be navigated and summary-to-detail exploration within a single system (Dubriwny and Rivards 2004). Both types of dashboard are used in urban control rooms, but they are also increasingly being displayed in mayor's offices, public buildings, and made accessible to the general public via dedicated websites along with the associated data (see Figure 1). In the latter case, other parties are able to use the data to conduct their own analyses and build city apps. 


\section{Figure 1: An at-a-glance and analytical city dashboard}
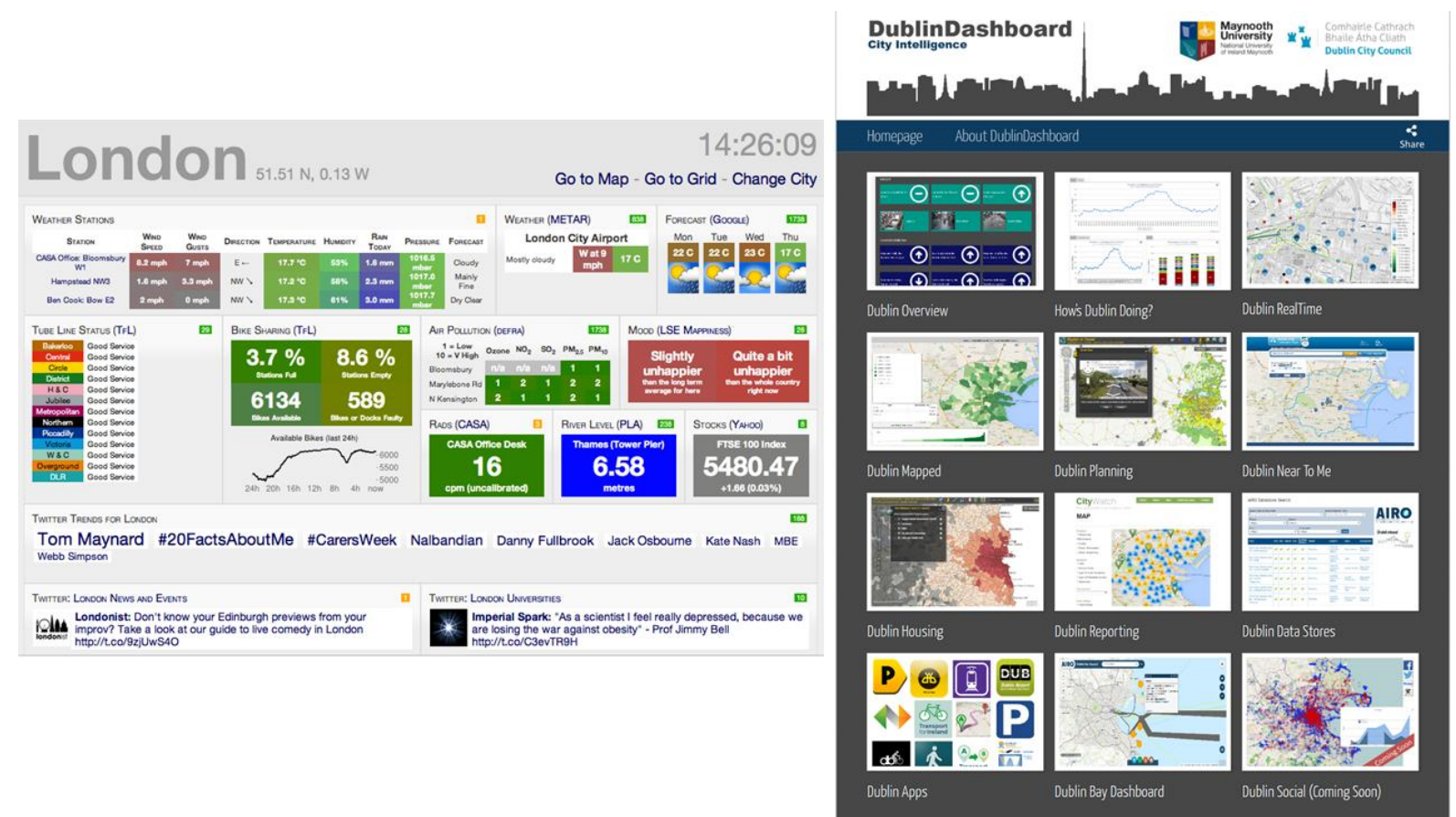

Typically, city dashboards display seven kinds of data:

(1) public administration data generated by local government, state agencies and government departments;

(2) official statistical data typically generated through surveys (e.g., a census or household/business surveys) administered by a national statistical institution or compiled from public administration data;

(3) operational data concerning the delivery of services by local government or specific agencies (e.g., a transport provider);

(4) scientific data relating to environmental conditions (e.g., weather, water levels, pollution, noise);

(5) crowdsourced data provided by citizens (e.g., reporting incidents);

(6) locative and social media data (e.g., geo-referenced data from social media, such as Twitter, accessed via APIs);

(7) derived data - that is, data that are created by combining and analysing the other six types of data (e.g., composite indicators, forecasts/predictions).

Most data within city dashboards - especially of the analytical variety - are sampled data generated on a set schedule (e.g., monthly, annually). Increasingly, however, city dashboards 
are incorporating big data, especially with respect to operational and scientific data. That is, data that are produced in real-time by the internet of things, but also through crowdsourcing and locative and social media.

The power and utility of urban dashboards is twofold. First, they act as cognitive tools that improve the user's 'span of control' over a large repository of voluminous, varied and quickly transitioning data (Brath and Peters 2004). As such, they enable a user to explore the characteristics and structure of datasets and interpret trends without the need for specialist analytics skills (the systems are point and click and require no knowledge of how to produce such graphics). Second, they purport to show in detail and often in real-time the state of play of cities. Urban dashboards seemingly enable users to know the city as it actually is through objective, trustworthy, factual data that can be statistically analyzed and visualised to reveal patterns and trends and to assess how it is performing vis-a-vis other places (Kitchin et al. 2015). They supply a rational, neutral, comprehensive and commonsensical media for monitoring and evaluating the effectiveness of urban services and policy, and to learn and manage through measurement. In so doing, dashboards facilitate the notion that it is possible to 'picture the totality of the urban domain', to translate the messiness and complexities of cities into rational, detailed, systematic, ordered forms of knowledge (Mattern 2014). In other words, they provide a powerful realist epistemology for monitoring and understanding cities, underpinned by an instrumental rationality in which 'hard facts' trump other kinds of knowledge and provide the basis for formulating solutions to urban issues (Kitchin et al. 2015; Mattern 2014; 2015). As such, they seemingly provide a neutral and value-free medium through which to make sense of, govern, and plan a city. And they expand the capacity to govern by extending forms of power/knowledge.

City dashboards are becoming increasingly important mechanisms for evaluating and guiding the work of city administrations and regimes of urban governance, though how they are implemented differs in ethos and form between cities. In general, initiatives fall into two broad camps, which together reveal the inherent tension within schemes between seeking to facilitate accountability, transparency and democracy, and enact forms of discipline, regulation and control (Hezri and Dovers 2006; de Waal 2014).

In some municipalities, city dashboard initiatives form the bedrock for performance management systems that are used to guide operational practices with respect to specified targets; to provide evidence of the success or failure of schemes, policies, units and personnel; and to guide new strategies, policy, and budgeting (Craglia et al. 2004; Behn 2014; Kitchin et al., 2015). Since 1999, Baltimore has used a system called CitiStat to 
implement a balanced scorecard approach to actively monitor the performance of city departments and guide the development of new policies and programmes and then assess the success of their implementation (Behn 2014). Every week city managers meet in a purpose built dashboard room to review performance and set new targets for the city as a whole and for each department, and discipline under-achievement (Gullino 2009). Dozens of other US cities have deployed similar systems. Such an approach is supported by an instrumental rationality that believes that such continual monitoring will positively influence the performance, quality, and productivity of city staff and services by reshaping behaviours and disciplining and rewarding actions with respect to targets (Hezri and Dovers 2006).

In other cases, municipalities use city indicator projects and associated dashboards in a more contextual way to provide robust city intelligence, which complements a variety of other information, to help inform policy making and implementation. In these cases, cities are understood to consist of multiple, complex, interdependent systems that influence each other in often unpredictable ways. Moreover, governance is seen as being complex and multi-level in nature requiring consensus building and cooperation across actors and scales, with the performance of systems and staff not easily reducible to performance metrics and targets. In other words, the city is not a machine that can be fine-tuned and managed through a set of simple data levers (Innes and Booher 2000). Dashboard information, however, is seen to provide valuable contextual insight that facilitates coordination, integration and interaction across departments and stakeholders by detailing trusted and authoritative datasets for the city and reducing uncertainty and insecurity in decision-making (Van Assche et al., 2010). In other words, dashboards and their data act as a normative and rational bridge between knowledge and policy (Hezri and Dovers 2006). A long-standing example of a contextual city indicator approach is that employed within Flanders, Belgium, where since the late 1990s a number of cities have employed a common City Monitor for Sustainable Urban Development, consisting of nearly 200 indicators, to provide contextual evidence for policy making (Van Assche et al. 2010).

\section{Control rooms}

Accompanying the embedding of computation into the fabric of cities has been the rollout of urban control rooms of varying kinds (e.g., security, transport, utilities) capable of handling real-time data. Control rooms utilising SCADA (supervisory control and data acquisition) systems can be traced back to the mid-twentieth century, but have multiplied with the growth of smart urbanism (Luque-Ayala and Marvin 2016). Early control rooms had a limited focus, 
usually to monitor and intervene in real-time into the performance of a closed system, for example the operation of an electricity grid. Over time, the remit of control rooms expanded to include more open systems, such as CCTV centres for monitoring public spaces, wherein control was enacted in part through self-disciplining; or traffic control rooms which mediate the production of space and time, synchronizing and optimizing the space-time rhythms of vehicular and pedestrian movement and minimizing disruption; or emergency management control rooms wherein control is exerted through coordination and direction of resources and personnel (Norris and Armstrong 1999; Coletta and Kitchin 2016; Luque-Ayala and Marvin 2016). While the CCTV and traffic control room are designed to manage the everyday and maintain normal operations, emergency management control rooms are designed to address exceptional conditions (Luque-Ayala and Marvin 2016). In general, control rooms work in the background, out of sight of public view, thus black-boxing the logic and operations of maintaining and regulating urban systems (Luque-Ayala and Marvin 2016). Increasingly, control rooms enact forms of automated management; that is, they utilise computation to monitor and regulate systems in automated, automatic and autonomous ways, wherein decision-making is ceded to algorithms (Dodge and Kitchin 2007).

More recently, a new breed of integrative city control room is being deployed, wherein several systems and their data are corralled into a single centre, with the walls between data and system silos collapsed to enable a more holistic and integrated view of city services and infrastructures. The example par excellence of an integrated urban control room is the Centro De Operacoes Prefeitura Do Rio in Rio de Janeiro, Brazil (COR) (see Figure X in Ayala-Luque/Marvin chapter). COR is a data-driven city operations centre that continuously monitors the city and also acts as a coordinated, emergency management centre. COR pulls together into a single location real-time data streams from thirty two agencies and twelve private concessions (e.g., bus and electricity companies), including traffic and public transport, municipal and utility services, emergency and security services, weather feeds, information generated by employees and the public via social media, as well as administrative and statistical data (Kitchin 2014; Luque-Ayala and Marvin 2016). These data are overseen and processed by a staff of 400 data operatives drawn from the city authority and the associated agencies supplying data. These operatives work across three shifts to provide twenty-four hour monitoring, analyses and services, with the information also being used for long-term planning. Each agency located in COR is autonomous and continues to maintain its own control room, operative systems and response protocols, with the COR providing a site of coordination and horizontal integration (Luque-Ayala and Marvin 2016). 
Luque-Ayala and Marvin (2016) contend that this new type of integrated control room produces a new specific form of governmentality by altering the logic of control in four ways. First, as noted the COR draws together several domains and data flows thus providing a coordinated meta-infrastructure that extends the logic of the control room to the totality of the city. Second, it collapses together control of the everyday (continual maintenance) and the emergency (discontinuous response to specific events), effectively managing the city as a site of perpetual crises. Third, it inverts the usual 'black box' character of control rooms by making its work visible to the public through daily media reports, its website, and enabling the public to visit the centre. Critically, the centre is not positioned as a locus of surveillance, policing, discipline, and law-enforcement (indeed, it is generally not used for these activities), but as a means to maintain infrastructure performance, minimize disruption to everyday life, and share information. Fourth, it enrols the public as a 'citizen sensors' (they supply information to the centre through social/locative media). In the latter case, the public "engage in the labour of being watched' (Monahan and Mokos 2013), active participants in a system that is beyond their control and modulates their behaviour. As Gabrys (2014) notes, such a process delimits the practices of citizenship, turning citizens into agents who feed back into control loops, rather expanding participatory and deliberative citizenship.

What this discussion highlights is that while the logics of control articulated by control rooms share similarities, how control is exercised within and mobilised through them is mutable across domain, systems and location, and evolves with new governmental arrangements and technological configurations. Importantly, how power is exercised through urban control rooms varies in three ways. First, there are different practices of control being exerted: intervention, self-disciplining, mediation, coordination, direction, optimization, and co-option. Each is designed to produce particular regulatory outcomes. Second, how systems are configured and operated varies across sites depending on management practices and governance context. Third, the extent of automated management varies with respect to the role of human operators in mediating their work. Some systems, or selected aspects of them, are configured to be human-in-the-loop (algorithms identify issues and suggest solutions but key decisions have to be made by the human operator), some human-on-the-loop (the system is automated but under the oversight of a human operator who can over-ride or take-over the system), and some human-off-the-loop (fully automated) (Coletta and Kitchin 2016).

\section{The logics of power and control in action}

\section{The Dublin Dashboard}


The Dublin Dashboard (http://www.dublindashboard.ie, see Figure 1) is an extensive, open, analytical dashboard launched in September 2014. It provides citizens, planners, policy makers and companies with an extensive set of data and interactive data visualizations about Dublin City, including real-time information, indicator trends, inter and intra-urban benchmarking, interactive maps, location-based services, a means to directly report issues to city authorities, and links to city apps. The data used in the dashboard is open and available for others to build their own apps. Unlike most urban dashboards, the Dublin Dashboard was initiated as a university research project, rather than by a city administration, with the aim of exploring the praxes and politics of developing such a dashboard (Kitchin et al., 2016). Shortly after initiation, the project started to work with Dublin City Council, with city officials helping to supply data and guide its development.

Although the dashboard is presented as a stable, authorative and technical assemblage of networked infrastructure, hardware, operating systems, assorted software, and data, achieved through neutral, objective processes of scientific conception, engineering and coding, it is also thoroughly social and political. Indeed, it is a complex socio-technical assemblage of actors (e.g., university researchers, city officials, other stakeholders) and actants (e.g., data, software, servers, standards) that work materially and discursively within a set of social and economic constraints, existing technologies and systems, and power geometries to assemble, produce and maintain the system. During development, ideas and choices concerning the aims, principals and technical approach were debated, refined, rescinded, re-instated and re-visioned. As such, whilst the narrative spun by companies, and often also by city management, suggests that the transition to a smart city is a smooth path of rollout and integration, the reality is a set of iterative processes of debate and compromise. Over time, the dashboard has continued to evolve and mutate. What this contingency and relationality means is that power and control is never fixed in either the creation or on-going operation of city dashboards (Kitchin et al., 2016).

That said, initial design does provide a certain degree of path dependency. As such, of particular importance to the logic of power and control in the development and use of the Dublin Dashboard were its aims and principles. Initially, the aim of the site was to provide a contextual, rather than a performance-management, dashboard for the city. The dashboard would enable the following questions to be answered: what are the present trends in Dublin? how does Dublin compare to other places? what is happening in the city right now? Added later were the questions: where are the nearest facilities/services to me? what are the spatial patterns of different phenomena? what are the future development plans for the city? how do 
I report issues about the city? how can I freely access data about the city? The underlying principles related to its development were: there would be no closed elements, with all of the visualizations on the site accessible to everyone; all of the data used on the site would be open in nature, enabling others to build their own apps; as much data as possible, regardless of source or type, would be made available through the site; where possible we would use open source tools; existing resources and apps would be used if they did a good job to remove duplication of effort; the site would be easy to use, with users requiring no mapping or graphing skills; and the site would be interactive allowing users to explore the data.

The Dublin Dashboard then sought to enact an approach that aligned with the principles of open government and the open data movement aimed at producing transparency, participation, empowerment, accountability, and evidence-informed decision- and policymaking. However, it did not embrace targets or performance-driven metrics designed to implement a form of city managerialism-by-data. This was one area of negotiation between the research team and the local authority. However, in the absence of already established targets, the lack of mechanisms to guide and react to performance vis-à-vis such targets, and the political nature of the project arbitrarily imposing targets, it became a moot point. The logic of the system was then neither discipline nor control-orientated in a direct way, but rather sought to provide evidence for citizens and city workers with respect to key aspects of everyday life. Nonetheless, the ability to make sense of, mobilize, and act on the data presented through the dashboard varies across individuals and organizations, and the data are still used to assess the performance of the city administration and to pressure for reforms and change through political and media campaigns. Moreover, because the data tools are used to shape policy formulation and to justify and underpin modes of governmentality, they inevitably shape and reproduce how people are governed. For all city dashboards, although the updating of the data and visualization tools can be automated, any control actions are usually human-in-the-loop in nature. That is, the translation of information into knowledge and action, and forms of governance and governmentality, are performed by people rather than algorithms.

\section{Traffic control system}

The Dublin Traffic Management and Incident Centre (TMIC) provides a single, integrated, $24 / 7$ control room to house the core traffic management systems for monitoring and controlling the road transportation network and traffic flow in the Greater Dublin Area, including dealing with major events and incidents (see Figure 2). To monitor and regulate the 
traffic flow the centre uses a network of 380 CCTV cameras, 800 sensors (inductive loops), a small number of Traffic Cams (traffic sensing cameras) used when inductive loops are faulty or the road surface is not suitable for them, a mobile network of approximately 1,000 bus transponders (controllers can also directly contact drivers if needed), phone calls and messages by the public to radio stations and operators, and social media posts. These networks of internet of things and citizen sensors produce a continuous flow of real-time data which are used to dynamically manage the road system.

Figure 2: A view from a controller's desk in the Dublin traffic control room

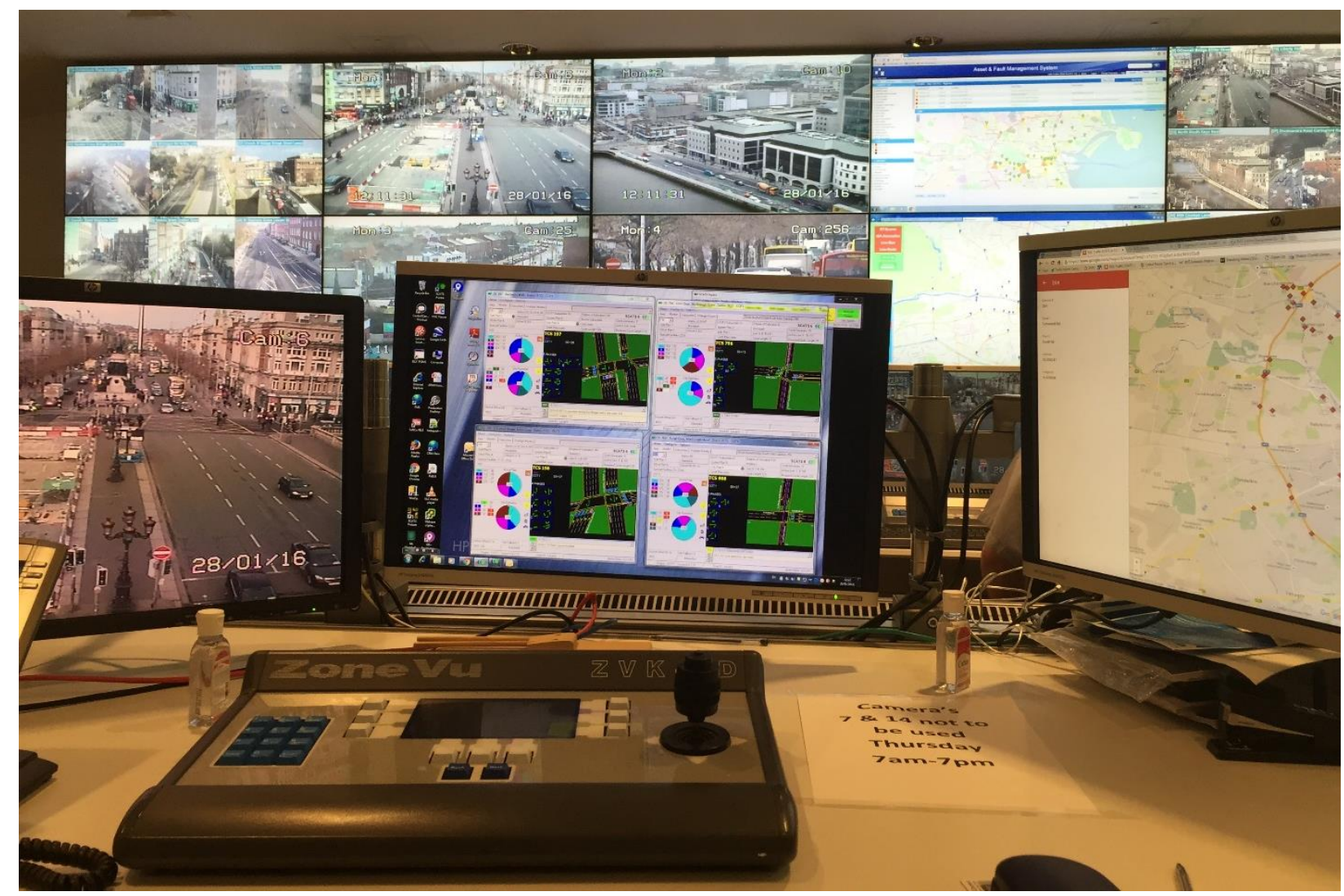

The core means by which the data are parsed and used to control traffic flow is via the adaptive traffic management system, SCATS (Sydney Coordinated Adaptive Traffic System). SCATS is an automated and adaptive system whose primary role is to manage the dynamic timing of signal cycles and phases at junctions for vehicles, cycles and pedestrians in order to ensure the optimal flow, minimize congestion and accidents, and manage incidents. The system is adaptive in the sense that it automatically calibrates the cycles and phases dependent on a set of programmed rules and the flow, speed, and density of traffic for each lane of traffic in previous cycles and phases. For example, the number of cars and the gaps 
between them as detected by the inductive loops denotes if a phase was too short or long, with the timing of the next phase re-calculated automatically by the system. Public buses benefit from prioritisation, so as they approach a junction the phasing will alter to accommodate their passage. By pressing a pedestrian crossing button at junction, people produce a temporary break in the phasing, closing down the main phase in order to run the pedestrian phase. Cycles are set to last a minimum of 40 seconds to a maximum 130 seconds, but in practice they rarely exceed 80 seconds or go below 60 seconds. This calculation is based on the pragmatic evaluation that the waiting time for a pedestrian crossing above 80 seconds would be too long. Given that alterations in cycles and phases flux, altering traffic flows across the system, changes in one location can sometimes produce congestion elsewhere, and the systems seeks to minimize such disruption by balancing competing demands across junctions.

By monitoring patterns over time, the TMIC staff can configure the setting of SCATS to take into account whether it is a weekday or weekend, as well as seasonal/daily rhythms and when schools are closed. In addition, operators can intervene and override the present or original SCATS settings. In this sense, SCATS is a human-on-the-loop system, wherein automation is used monitor and regulate traffic flow but operators oversee and can manually override its work. To oversee SCATs, a controller is presented with a dashboard-like interface (Figure 3). The right hand part of the screen displays a junction, the various traffic lanes, and their phases, and the left hand part the length of time for each phase. Interventions are circumscribed by the initial configuration of the system by Intelligent Transportation System staff, which in turn refer to the Traffic Signs Manual by the National Roads Authority that sets rules on the minimum and maximum times for phases. If, for example, operators try to go below the minimum safety times for green or red time on a different phase SCATS will automatically override the modification attempt with the original configuration.

As well as directly altering the phasing of junctions and the rhythms of traffic flow, much of the data utilised in the traffic control room is shared with the public via a number of channels, enabling people to see and interpret the data themselves and self-regulate their interactions with the traffic system and to manage time-based decisions for journey planning. For example, real-time information about the expected arrival time of buses and luas trams are shared via smartphone apps, websites, and on-street dynamic signs. Details of congestion and traffic accidents are shared via radio bulletins (one of the desks in the control room is reserved for an AA Roadwatch operator who communicates traffic news to radio stations throughout the day, and three desks host Dublin City FM's live broadcast of traffic news and 
music between 7-10am and 4-7pm, Monday to Friday (http://www.dublincityfm.ie/). These broadcasts inform and pacify travellers and enable them to seek alternative routes. Data from the systems are openly shared via Dublinked and displayed in the Dublin Dashboard.

\section{Figure 3: The SCATS interface}

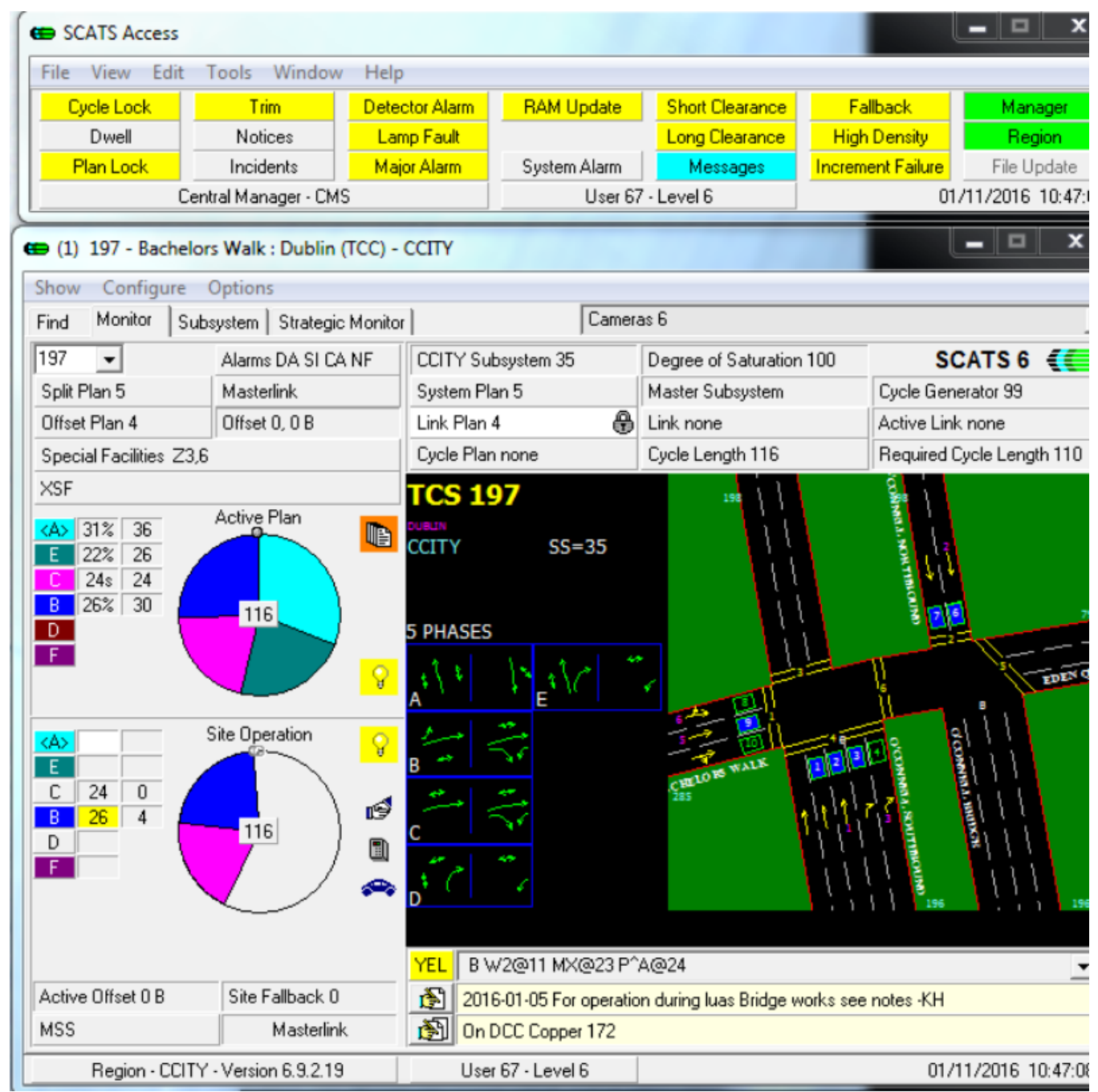

SCATS is a second-order cybernetic system that enacts a human-on-the-loop form of automated management to dynamically modulate the movement of people while also enrolling them as citizen sensors. At present, the Dublin TMIC is not used for routine surveillance or policing. While the centre pulls together data from a number of different systems, including from citizens, and one desk is reserved for Gardai (police) use, the centre does not generate or store indexical data (e.g., it does not employ automatic number plate recognition cameras), nor does it record video footage. Nor is it responsible for speed, redlight, or bus lane cameras. That said, the Gardai do have their own access to the camera 
network, which they use for policing. Moreover, the centre can be used for managing major events and emergencies. As Monahan (2007) details, traffic control rooms are particularly susceptible to control creep, with the purpose of managing traffic flow being extended to include routine surveillance, policing, and security work, and the data generated shared with other state agencies. With this control creep the governmentality enacted by traffic control rooms shifts. In addition, he notes that while traffic control rooms are portrayed as socially and political neutral, and impartial in how they manage traffic, they nonetheless support certain values and socially sort the users of city space, 'valorizing certain mobilities over others, while normalizing unequal experiences of space' (Monahan 2007: 373). As such, intelligent transport systems sustain 'ongoing neoliberal development patterns by emphasizing 'pipes' over places, maximizing the flow of privately owned vehicles through those pipes' (p.385), and privileging the support for certain mobilities over others (private over public transportation, driving over walking or bicycling).

\section{Discussion and conclusion}

There is little doubt that urban informatics, and smart city technologies in general, are changing urban governmentality and governance. At a broad level, urban informatics through their embedding of computing into the fabric of cities and use of computation to manage city services and infrastructures are shifting governmentality from disciplinary forms to those of social control. Here, rather than governmentality concentrating on molding subjects and restricting action within spatial enclosures, it seeks to modulate affects and channel action across space. However, as our discussion of city dashboards and urban control rooms in general, and our two case studies in particular, reveal, this transformation in governmentality is uneven and diversely constituted. Indeed, there is much variety in the configuration and deployment of socio-technical assemblages - even within particular technological domains such city dashboards and control rooms - and in their logics of control, tactics and operational techniques. For example, systems vary with the extent to which they implement forms of automated management (with humans in-, on-, off-the-loop) and in how they seek to enact governmentality: through modes of surveillance and discipline or capture and control; through systems that are 'black-boxed' or transparent; through regulatory techniques such as coercion, co-option, self-disciplining, punish, modulation, intervention, mediation, coordination, direction, and optimization.

The logics of control articulated by urban informatics then is diverse and mutable across domain, system, location, and context. In a city with a range of urban informatics 
deployments, several related and overlapping forms of governmentality can enacted and promoted by different entities and be at work at the same time. Both the Dublin Dashboard and the Dublin TMIC pull together and integrate a range of urban data. Both seek to enrol citizen sensors to crowdsource additional data, and both openly share some of their underlying data with the public. The Dublin Dashboard though is rooted in an open data/government ethos and set of principles designed to promote openness, transparency and contextually-based, evidence-informed policy making, and it is very much a human-in-theloop configuration with regards to action. In contrast, the Dublin TMIC seeks to produce a continuous modulation in the flow of traffic using SCATS, a second-order cybernetic system of control, and has a human-on-the-loop configuration. It aims to optimize the performance of the road network, minimizing congestion and maximizing flow and speed of movement. This diversity in ethos, purpose, and logics of control multiplies across the range of smart city technologies deployed in a city (e.g., city operating systems, predictive policing, coordinated emergency management, smart travel cards, smart parking, bike-share schemes, smart energy grids, smart lighting, smart metering, sensor networks, building management systems, smart homes, social and locative media, city apps, civic hacking, etc.). It seems then that urban informatics illustrates Ong's (2006) contention that at any one time there are varieties of governmentalities at work in the neoliberal city.

However, heeding Brenner et al., (2010) caution about overstating the diversity and mutability of governmentality and divorcing its forms from their wider context, it is important, we believe, to consider a number of related questions. How do smart city technologies and initiatives and their associated governmentality and logics of control fit together? Do they work in concert or in opposition to one another? How do they dovetail with other assemblages and practices of governance? Do they form part of a wider set of 'patterned and patterning processes' and work within, reproduce and evolve the wider political economy and regulatory context? In the context of Dublin urban informatics and smart city initiatives are situation within a neoliberal urban economy (Kitchin et al., 2012; MacLaran and Kelly 2014), coordinated and promoted through Smart Dublin (http://www.smartdublin.ie), a collaboration between the four local authorities that is also responsible for Dublinked (http://www.dublinked.ie), the city's open data respository. Smart Dublin's mission is to stimulate the economic competitiveness of the Dublin Region through public-private partnerships, to drive public sector efficiencies and improve services, and to promote transparency and open government. While the latter objective seems to run counter to the first two, the primary vehicle for its delivery is Dublinked, established in 2011 as an 
economic initiative designed to foster the creation of an open data economy. In addition, civic hacking in Ireland has largely been state and corporate sponsored. For example, Code for Ireland is backed by the Irish government, its meetups take place in Google, Facebook and Linkedin's headquarters in Dublin, and many of its attendees work in the Irish tech industry. Rather than questioning and challenging established orders, smart city initiatives in the city work together in a loose collaborative and overlapping arrangement to promote, enact and reinforce the neoliberal agenda.

What is required then is for the governmentalities of specific smart city assemblages to be unpacked and how they work in collaborative concert charted. To date, such an endeavour has not been undertaken. Analysis has either been general, cursory and lacking empirical depth, or focused on excavating the logics of control of particular sites and technologies. This needs to be complemented with a mapping in detail of the wider overlapping governmentalities of the smart city, how initiatives interlink and work together to legitimize and (re)produce technocratic forms of governance, and how the practices and governmentalities of smart city endeavours coalesce with and extend those framed and enacted through other means. Such a mapping, we believe, needs critical attention if we are to understand the logics of control of smart cities, how urban informatics are producing particular formulations of the neoliberal city, and how we might envisage and create a different kind of smart city.

\section{Acknowledgements}

The research for this chapter was provided by a European Research Council Advanced Investigator Award, 'The Programmable City' (ERC-2012-AdG-323636) and a Science Foundation Ireland grant, 'Building City Dashboards' (15/IA/3090).

\section{References}

Agre, P. (1994) Surveillance and capture: Two models of privacy. Information Society 10(2): 101-27.

Batty, M. (2013) Urban Informatics and Big Data. London: CASA, University College London. http://www.spatialcomplexity.info/files/2015/07/Urban-Informatics-and-BigData.pdf (last accessed 2 Jan 2017) 
Behn, R.D. (2014) The PerformanceStat Potential: A Leadership Strategy for Producing. Brookings Institution Press/Ash Center: New York.

Brath, R. and Peters, M. (2004) Dashboard design: Why design is important. DM Direct, October 2004.

Braun, B.P. (2014) A new urban dispositif? Governing life in an age of climate change. Environment and Planning D: Society and Space 32: 49-64.

Brenner, N., Peck, J. and Theodore, N. (2010) Variegated neoliberalization: geographies, modalities, pathways. Global Networks 10(2): 182-222.

Coletta, C. and Kitchin, R. (2016) Algorhythmic governance: Regulating the 'heartbeat' of a city using the Internet of Things, Programmable City Working Paper 22, https://osf.io/bp7c4/

Craglia, M., Leontidou, L., Nuvolati, G. and Schweikart, J. (2004) Towards the development of quality of life indicators in the 'digital' city. Environment and Planning B 31(1): 51-64.

Davies, W. (2015) The chronic social: relations of control within and without neoliberalism. New Formations 84(84-85): 40-57.

de Waal, M. (2014) The City as Interface: How New Media Are Changing the City. Nai010 Publishers: Amsterdam.

Deleuze, G. (1992) Postscript on the societies of control. October 59 3-7

Dodge, M. and Kitchin, R. (2007) The automatic management of drivers and driving spaces. Geoforum 38(2): 264-75.

Dubriwny, D. and Rivards, K. (2004) Are You Drowning in BI Reports? Using Analytical Dashboards to Cut Through the Clutter. DM Review, April 2004, http://www.advizorsolutions.com/press/Cut\%20Through\%20The\%20Clutter.pdf (last accessed 4 June 2014).

Few, S. (2006) Information Dashboard Design: The Effective Visual Communication of Data. O'Reilly.

Forrester, J.W. (1969) Urban Dynamics. MIT Press: Cambridge.

Foucault, M. (1977) Discipline and Punish. Allen Lane, London.

Foucault, M. (1978) The History of Sexuality, Volume One. Random House, New York.

Foucault, M. (1991). 'Governmentality', in Burchell, G., Gordon, C. and Miller, P. (eds) The Foucault Effect: Studies in Governmentality. Chicago, IL: University of Chicago Press, pp. 87-104. 
Gabrys, J. (2014) Programming environments: environmentality and citizen sensing in the smart city. Environment and Planning D 32(1): 30-48.

Gray, S., Milton, R. and Hudson-Smith, A. (2013) Visualising real-time data with an interactive iPad video wall. Talisman. http://www.geotalisman.org/files/2013/05/MethodsNewsSpring2013_DRAFT_Part7.pdf (last accessed 29 August 2016).

Gullino, S. (2009) Urban regeneration and democratization of information access: CitiStat experience in Baltimore. Journal of Environmental Management 90: 2012-2019.

Hezri, A.A. and Dovers, S.R. (2006) Sustainability indicators, policy and governance: Issues for ecological economics. Ecological Economics 60: 86-99

Innes, J. and Booher, D.E. (2000) Indicators for sustainable communities: A strategy building on complexity theory and distributed intelligence, Planning Theory \& Practice 1(2): 173186.

Kitchin, R. (2014) The Data Revolution: Big Data, Open Data, Data Infrastructures and Their Consequences. Sage, London.

Kitchin, R. and Dodge, M. (2011) Code/Space: Software and Everyday Life. MIT Press, Cambridge, MA.

Kitchin, R., O’Callaghan, C., Boyle, M., Gleeson J. and Keaveney, K. (2012) Placing neoliberalism: The rise and fall of Ireland's Celtic Tiger. Environment and Planning A 44(6): 1302-1326.

Kitchin, R., Lauriault, T. and McArdle, G. (2015) Knowing and governing cities through urban indicators, city benchmarking and real-time dashboards. Regional Studies, Regional Science 2: 1-28.

Kitchin, R., Maalsen, S. and McArdle, G. (2016) The praxis and politics of building urban dashboards. Geoforum 77: 93-101

Klauser, F., Paasche, T. and Soderstrom, O. (2014) Michel Foucault and the smart city: power dynamics inherent in contemporary governing through code. Environment and Planning D: Society and Space 32(5): 869-885.

Krivỳ, M. (2016, online first) Towards a critique of cybernetic urbanism: The smart city and the society of control. Planning Theory

Larner, W. (2003) 'Neoliberalism?’ Environment and Planning D: Society and Space 21: 509-12. 
Luque-Ayala, A. and Marvin, S. (2016). The maintenance of urban circulation: an operational logic of infrastructural control. Environment and Planning D: Society and Space 34(2): 191-208.

MacLaran, A. and Kelly, S. (2014) Neoliberal Urban Policy and the Transforming of the City: Reshaping Dublin. Palgrave: Basingstoke.

Martinez, D.E. (2011) Beyond disciplinary enclosures: Management control in the society of control. Critical Perspectives on Accounting 22(2): 200-211.

Mattern, S. (2014) Interfacing urban intelligence. Places Journal https://placesjournal.org/article/interfacing-urban-intelligence/ (last accessed 13 Jan 2017).

Mattern, S. (2015) Mission Control: A history of the urban dashboard, Places Journal https://placesjournal.org/article/mission-control-a-history-of-the-urban-dashboard/ (last accessed 13 Jan 2017).

Monahan, T. (2007) 'War rooms' of the street: Surveillance practices in transportation control centers. The Communication Review 10(4): 367-389.

Monahan, T. and Mokos, J.T. (2013) Crowdsourcing urban surveillance: The development of homeland security markets for environmental sensor networks. Geoforum 49: 279-288.

Norris, C. and Armstrong, G. (1999) CCTV and the social structuring of surveillance. Crime Prevention Studies 10(1): 157-178).

Ong, A. (2006) Neoliberalism as Exception: Mutations of Citizenship and Sovereignty, Durham, NC: Duke University Press.

Peck, J. and Theodore, N. (2007) Variegated capitalism. Progress in Human Geography 31(6): 731-772.

Sadowski, J. and Pasquale, F. (2015) The spectrum of control: A social theory of the smart city. First Monday 20(7). http://journals.uic.edu/ojs/index.php/fm/article/view/5903 (accessed 6 Jan 2017)

Townsend, A. (2013) Smart Cities: Big Data, Civic Hackers, and the Quest for a New Utopia. W.W. Norton \& Co, New York.

Van Assche, J., Block, T. and Reynaert, H. (2010) Can community indicators live up to their expectations? The case of the Flemish City Monitor for Livable and Sustainable Urban Development. Applied Research Quality Life 5: 341-352.

Vanolo, A. (2014) Smartmentality: The Smart City as Disciplinary Strategy. Urban Studies 51(5): 883-898. 